\title{
Integrated Voltage Regulation and Current-sensorless Power Tracking Control for A DC Hybrid Power System
}

\author{
Yanhui Xie, Jing Sun, James S. Freudenberg
}

\begin{abstract}
Hybrid power systems combine two or more complementary power generation technologies to achieve the system performance that is not possible for those involving a single power technology. The complicated dynamic interactions of the hybrid power system elements, coupled with stringent safety, power quality and efficiency requirements, impose challenging control and dynamic optimization problems. This paper presents a novel approach that addresses the voltage regulation and power tracking problems for hybrid DC power system. A DC power network consisting of two power sources is considered. A nonlinear dynamic model is developed, and a nonlinear controller is employed to achieve: (1) DC bus voltage regulation; (2) current sensorless power tracking control. Both the dynamic model and the nonlinear controller are validated with simulation and experiment results. The results show that the nonlinear controller can effectively achieve the system performance objective.
\end{abstract}

\section{INTRODUCTION}

$\mathbf{H}$ YBRID Power Systems combine two or more complementary power generation technologies to achieve the system performance that is not possible for those involving a single power technology. For example, when combining renewable energy technologies such as wind energy [1] and photovoltaic energy [2] with traditional power generation technologies, it can provide low cost and highly reliable power solutions for island and remote area applications. Meanwhile, state-of-the-art fuel cell technologies bring in the low emission and high efficiency option of power generation, making them very attractive for automotive powertrain [3] and shipboard power systems [4]. In general, hybrid power systems can be categorized into AC Hybrid Power Systems (AHPS) and DC Hybrid Power Systems (DHPS), depending on the types of power bus used.

For mobile applications, typical hybrid power systems are of DC type and are used as the isolated power solution with no grid connections. As such, their dynamic interactions among heterogeneous power sources as well as these between the sources and loads are more intricate. The wide range of operating conditions, the requirements for fast power response and load following, coupled with the stringent constraints of high power quality and system reliability, have imposed challenges for control of the DHPSs with multiple power converters whose dynamic behaviors are

This work was sponsored by the U.S. Office of Naval Research (ONR) under Grants No. N00014-03-1-0983 and N00014-05-1-0533.

Yanhui Xie, Jing Sun are with the Department of Naval Architecture and Marine Engineering, University of Michigan, Ann Arbor, Michigan 48109 USA (e-mail: yhxie@umich.edu; jingsun@umich.edu).

James S. Freudenberg is with the Department of Electrical Engineering and Computer Science, University of Michigan, Ann Arbor, Michigan 48109 USA (e-mail: jfr@eecs.umich.edu). highly nonlinear. For example, power imbalance in DHPSs will cause voltage fluctuation and adversely affect the power quality. In addition, the power management of the hybrid power system will entail complex control and dynamic optimization problems, that involve the dynamic allocation and operation of multiple power sources, power converters and loads. Therefore, coordinating the power converters of the DC hybrid power system to achieve power tracking while regulating the DC bus voltage is a critical task for DHPS power management.

Conventional current mode control [5] of power converters is based on the sensing of either the peak current [6] or the average current [7] of the inductor. In [8], the authors proposed a sensorless current mode control approach by reconstructing the inductor current to improve the performance in the presence of noise and to enhance the load range. Publications on the current control of multiple power converters have been mostly focused on parallel DC/DC PWM converter systems wherein multiple parallel connected converters draw power from the same source to feed the loads. To improve the system reliability, the current sharing problem has been extensively addressed [9]. Control schemes for parallel power converters can be roughly categorized into the droop method [10] and active current sharing technique [11]. The goals of both schemes are to make the parallel power converters having equal output current. The main focus of most of those publications has been on the architectures of the control schemes, and the control design are based on linearized small signal model without considering the highly nonlinear inherent dynamics of the power converters.

In this paper, we present a control-oriented large signal dynamic model of a DC hybrid power system with two Full Bridge (FB) DC/DC converters. This model is developed based on averaging the inductor current over the switching period, and is verified both by simulations using a detailed physical based model and experiments using a hardware testbed. Although dynamic modeling of a single DC/DC power converter has been extensively studied in the literature, the systematic dynamic modeling of a power conditioning system composed of several full bridge DC/DC converters has not been reported in the literature, to our best knowledge. Based on the dynamic model, a simple nonlinear controller is developed in this work to achieve: (1) DC bus voltage regulation; and (2) current sensorless power tracking. The simulation and experiment results show that the nonlinear controller can effectively achieve the control objectives.

The rest of this paper is organized as follows: In Section II, the hardware configuration of the DHPS consisting of 
two power sources, two DC/DC converters and a load will be presented. The simulation platform which is used as the virtual hardware to complement the hardware test is also presented. Section III is focused on the large signal dynamic modeling of the DHPS. Simulation and experiment validation will be discussed in Section IV. Section V will be devoted to the nonlinear controller development and performance evaluation, followed by the conclusions in Section VI.

\section{HARDWARE CONFIGURATION AND SIMULATION PLATFORM OF THE DHPS}

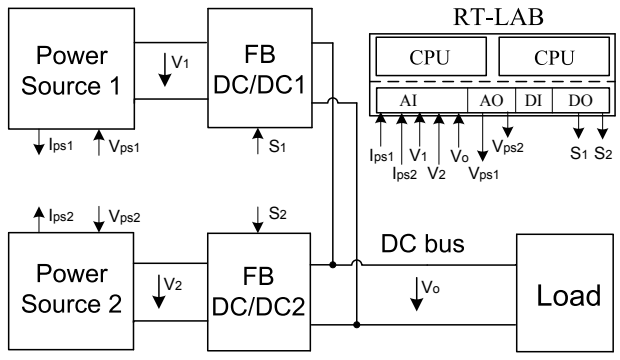

Fig. 1: Configuration of the DHPS testbed.

Fig.1 shows the configuration of the DHPS to be investigated in this paper. The system is composed of two power sources, two FB DC/DC converters and an electronic load. Its architecture reflects some of the hybrid power systems used for automotive and shipboard Auxiliary Power Unit (APU) applications.

For our laboratory scale studies, a $1 K W$ system is developed and used as the platform for experimental investigation. RT-LAB ${ }^{\circledR}$ based control and data acquisition is used to support the modeling and control development effort. For this work, the RT-LAB ${ }^{\circledR}$ system serves the following three functions: (1) as the real-time simulator for the power sources; (2) as the control unit to generate the $10 \mathrm{kHz}$ modulation signals for the two full bridge DC/DC converters according to feedback information; (3) as the data acquisition device to acquire and store experiment data to enable detailed offline analysis. In this study, we consider the power sources combination of a fuel cell stack and a gas turbine/generator/rectifier set, which have complementary characteristics and are considered for shipboard applications. Two programmable power supplies are employed to emulate the fuel cell and the gas turbine/generator/rectifier set respectively using the corresponding models to represent their dynamic characteristics. Each of the two isolated FB DC/DC converters in Fig. 1 can deliver $1 K W$ from the power source to the load. A pure resistance $R$ is considered as the load for the DHPS.

A physical model is also developed using MATLAB ${ }^{\circledR}$ physical modeling toolset SimPowerSystems ${ }^{\circledR}$ and ARTEMIS $^{\circledR}$ and RT-EVENTS ${ }^{\circledR}$ toolsets of RT-LAB ${ }^{\circledR}$. It has the same configuration as shown in Fig.1 and the same parameters as the real hardware. The specific parameters for this platform is shown in Table I and Table
II. This physical model can serve as virtual hardware testbed for the subsequent model development, model validation and control algorithm verification effort.

TABLE I: Power source parameters

\begin{tabular}{cll}
\hline \hline Power sources & Rated Power & Voltage \\
\hline Fuel cell & $150 \mathrm{~W}$ & $70 \mathrm{~V}$ \\
& $1 \mathrm{KW}$ & $55 \mathrm{~V}$ \\
GT/Rectifier & Full range & $58 \mathrm{~V}$ \\
\hline
\end{tabular}

TABLE II: FB DC/DC converter parameters

\begin{tabular}{ll}
\hline \hline Components c & Parameters \\
\hline$L_{1}$ & $11.5 u \mathrm{H}$ \\
$L_{2}$ & $9.6 u \mathrm{H}$ \\
$C_{1}$ & $8160 u \mathrm{~F}$ \\
$C_{2}$ & $8160 u \mathrm{~F}$ \\
$C_{o}$ & $1410 u F$ \\
Turn ratio $\left(T_{1}\right)$ & 2 \\
Turn ratio $\left(T_{2}\right)$ & 2 \\
\hline
\end{tabular}

\section{LARGE SIGNAL DYNAMIC MODELING OF DHPS}

\section{A. Dynamic model derivation of a single converter}

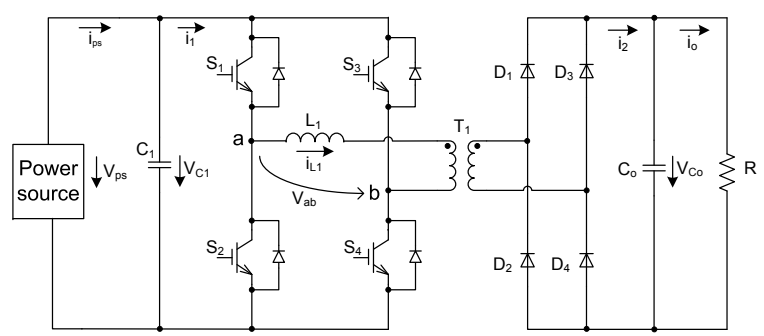

Fig. 2: Configuration of the single FB DC/DC converter power stage.

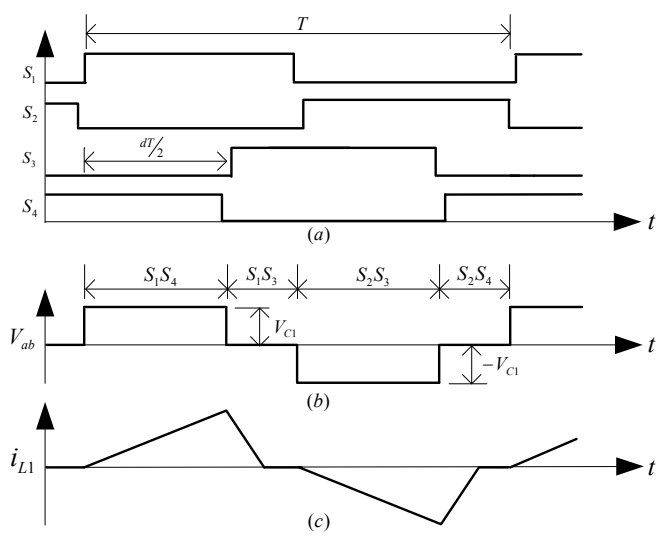

Fig. 3: Phase shift modulation of FB DC/DC converter.

Fig. 2 delineates the configuration of a single FB DC/DC converter which is modulated by the phase shift modulation strategy depicted in Fig.3a, where $d$ is the shifted phase and $T$ is the switching period. Given the circuit shown in 
Fig.2, this converter can be modeled as a third order dynamic system with states $i_{L_{1}}, V_{C_{1}}$, and $V_{C_{o}}$. Referring to Fig.3a, even if we ignore the four dead zones which are used to protect the power switches, there are four operation modes for each switching period, characterized by $S_{1} S_{4}, S_{1} S_{3}$, $S_{2} S_{3}$ and $S_{2} S_{4}$ respectively. These four operation modes take turns in charging and discharging the inductor bidirectionally, at a switching frequency of $10 \mathrm{kHz}$. Consequently, the inductor current $i_{L 1}$ (Fig.3c) varies in duty ratio, slope and peak values at $10 \mathrm{kHz}$ frequency. It is worthwhile to point out that the following two characteristics of the system operation can lead to a simplified model. First, the variation of the two voltage states $V_{C_{1}}$ and $V_{C_{o}}$ for each switching period is very small. Second, for the purpose of current or power control, it is not the instantaneous value of $i_{L 1}$ but the average current over the switching period that defines the power and current response. Therefore, by substituting the moving average of the fast dynamics variable $i_{L 1}$ into the slow dynamics variables $\left(V_{C_{1}}, V_{C_{o}}\right)$ subsystem, the averaging model of the slow subsystem can be obtained.

Using the relation $i_{2}=\left|i_{L 1}\right| / n$, where $n$ is the transformer turn ratio, we can derive the following expression for the average value of $i_{1}$ and $i_{2}$ over the switching period:

$$
\begin{aligned}
\hat{i}_{1} & =\frac{1}{T} \int_{t-T}^{t} i_{1}(t) d t=\frac{T\left(n V_{C_{1}}-V_{C_{o}}\right) d^{2}}{4 n L_{1}} \\
\hat{i}_{2} & =\frac{1}{T} \int_{t-T}^{t} i_{2}(t) d t=\frac{1}{T} \int_{t-T}^{t} \frac{\left|i_{L 1}(t)\right|}{n} d t \\
& =\frac{T V_{C_{1}}\left(n V_{C_{1}}-V_{C_{o}}\right) d^{2}}{4 n L_{1} V_{C_{o}}} .
\end{aligned}
$$

Then the dynamic model of the FB DC/DC converter can be expressed as:

$$
\begin{aligned}
\frac{d V_{C_{1}}}{d t} & =\frac{1}{C_{1}}\left(i_{p s}-\hat{i}_{1}\right), \\
\frac{d V_{C_{o}}}{d t} & =\frac{1}{C_{o}}\left(\hat{i}_{2}-\frac{V_{C_{o}}}{R}\right) .
\end{aligned}
$$

Therefore, by using (1) and (2), the third order system with high frequency switching and multiple modes is reduced to the second order model without mode switching.

\section{B. Dynamic model derivation of DHPS}

For the DHPS shown in Fig.4, since the output of the two $\mathrm{DC} / \mathrm{DCs}$ are connected to the DC bus, it is equivalent that there are two current sources $i_{2}$ and $i_{4}$ charge the capacitor $C_{o}$, where,

$$
C_{o}=C_{o 1}+C_{o 2}
$$

The general dynamic model of this DHPS can then be described by:

$$
\begin{aligned}
\frac{d V_{C_{1}}}{d t} & =\frac{1}{C_{1}}\left(i_{p s 1}-\frac{T\left(n V_{C_{1}}-V_{C_{o}}\right) d_{1}^{2}}{4 n L_{1}}\right), \\
\frac{d V_{C_{2}}}{d t} & =\frac{1}{C_{2}}\left(i_{p s 2}-\frac{T\left(n V_{C_{2}}-V_{C_{o}}\right) d_{2}^{2}}{4 n L_{2}}\right), \\
\frac{d V_{C_{o}}}{d t} & =\frac{1}{C_{o}}\left(\frac{T V_{C_{1}}\left(n V_{C_{1}}-V_{C_{o}}\right) d_{1}^{2}}{4 n L_{1} V_{C_{o}}}\right. \\
& \left.+\frac{T V_{C_{2}}\left(n V_{C_{2}}-V_{C_{o}}\right) d_{2}^{2}}{4 n L_{2} V_{C_{o}}}-\frac{V_{C_{o}}}{R}\right) .
\end{aligned}
$$

This model structure can be easily extended to a DHPS with $\mathrm{m}$ power sources.

For the system under investigation, Power Source 1 is the fuel cell while Power Source 2 is the gas turbine/generator/rectifier set. For the navy shipboard power system, given the facts: (1) the total ship service load is only $10 \% \sim 20 \%$ of the rated power of the gas turbine/generator, any ship service load change will not cause large voltage variation of the main $\mathrm{AC}$ bus; (2) the output voltage of the $\mathrm{AC} / \mathrm{DC}$ rectifier is regulated, therefore the assumption can be made that the output voltage for the gas turbine and rectifier set is constant ( $V_{C_{2}}=V_{p s 2}=E$ ). With this assumption, the model for the DHPS can be further simplified as:

$$
\begin{aligned}
\frac{d V_{C_{1}}}{d t} & =\frac{1}{C_{1}}\left(i_{p s 1}-\frac{T\left(n V_{C_{1}}-V_{C_{o}}\right) d_{1}^{2}}{4 n L_{1}}\right), \\
\frac{d V_{C_{o}}}{d t} & =\frac{1}{C_{o}}\left(\frac{T V_{C_{1}}\left(n V_{C_{1}}-V_{C_{o}}\right) d_{1}^{2}}{4 n L_{1} V_{C_{o}}}\right. \\
& \left.+\frac{T E\left(n E-V_{C_{o}}\right) d_{2}^{2}}{4 n L_{2} V_{C_{o}}}-\frac{V_{C_{o}}}{R}\right) .
\end{aligned}
$$

The low complexity of the DHPS model described by (9)(10) would be very helpful for controller development. This model is validated againest both the physical model and the real hardware testbed.

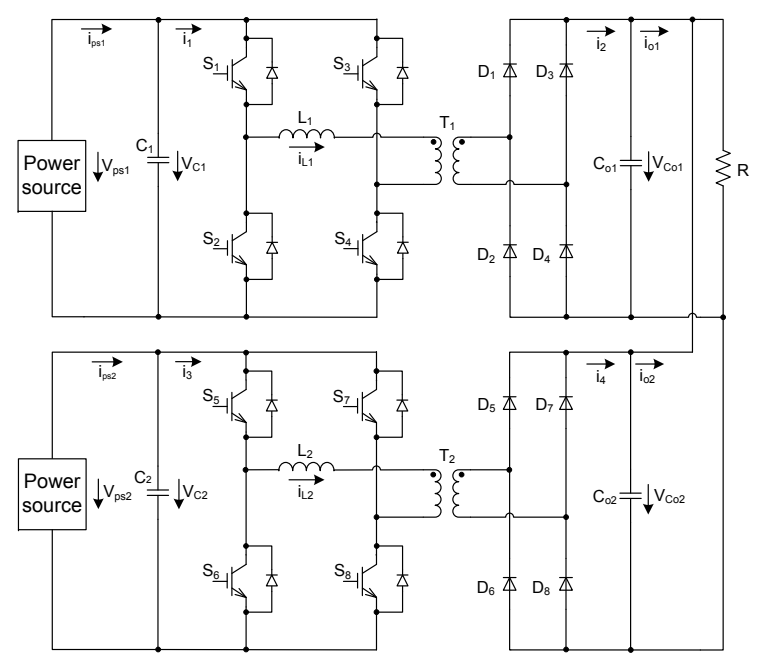

Fig. 4: Configuration of DHPS power stage. 

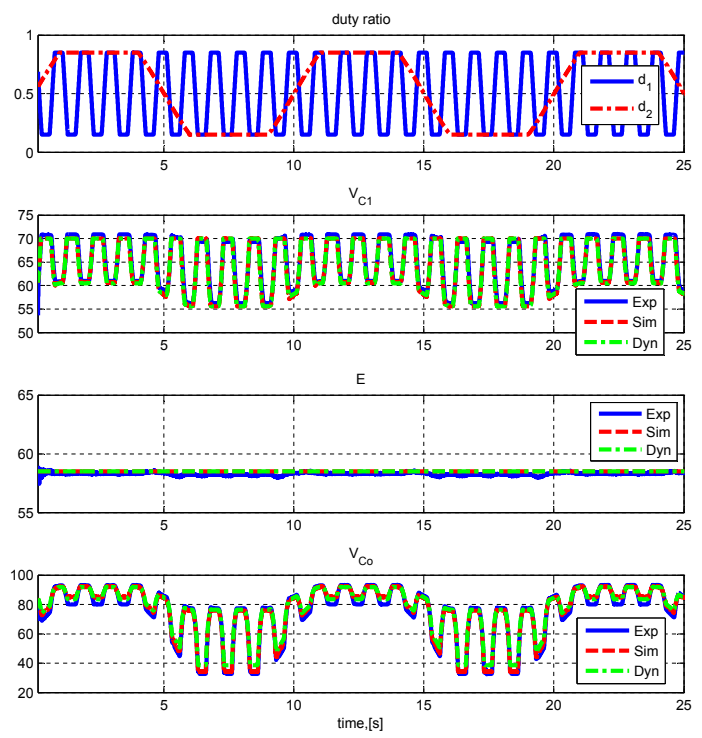

(a)
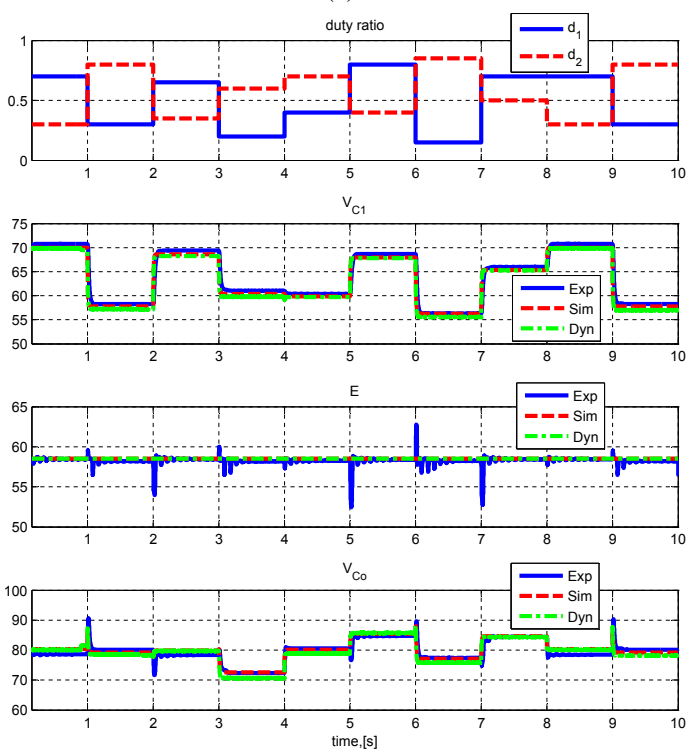

(b)

Fig. 5: Validation of the model with experiment.

\section{Model VAlidation}

To verify the dynamic model of the DHPS, open loop simulations of the dynamic model (9)-(10) as well as the physical model are performed using the MATLAB/SimPowerSystems ${ }^{\circledR}$ toolbox with truncated sinusoidal signals and step signals as control signals $d_{1}$ and $d_{2}$. The same control signals $d_{1}, d_{2}$ as employed in the simulation are also used in the open loop test using the DHPS real hardware testbed.

Fig.5a shows the transient responses of the low order dynamic model, the physical model simulation and the hardware testbed experiment when $d_{1}$ and $d_{2}$ are the truncated sinusoidal signals with $0.1 \mathrm{~Hz}$ and $1 \mathrm{~Hz}$ frequency respectively. The response of the dynamic model is very close to that of the physical model and the hardware testbed. Fig.5b shows the transient response of the low order dynamic model, the physical model simulation and the hardware testbed experiment of the DHPS with step changes in duty ratio $d_{1}, d_{2}$. Duo to limited output capacity of the power supply used to emulate constant voltage source, the output voltage of one of the sources (the gas turbine/generator/rectifier set) can not be kept constant during the experiment when step change in the load is introduced, as shown by the significant ripple noise in $E$ ("Exp" of the third window of Fig.5b). This phenomenon has not happened for both the low order dynamic model and the physical model simulations. Other than that, the low order dynamic model captures the behavior of the real device very well.

The open loop test results of this section lead to the conclusion that the dynamic behavior of the DHPS can be accurately represented by the dynamic model. It is noteworthy to point out that no calibration or data regression is involved in the model development. Therefore, the model development process delineated in Section III can be carried out systematically.

\section{Controller Development}

In this section, we will discuss the development of the control algorithms. It should be noted that we assume there is a high level power management subsystem to compute the desired output trajectories of the DHPS. The DHPS serves as the power system actuator, acting on the information on load $R$, the desired power splitting ratio $k$ and the desired bus voltage $V_{o d}$, all set by the upper level power management system. The control objectives at the DHPS level are DC bus voltage regulation and power splitting ratio tracking for given load. Before proceeding to the control analysis, we first show, through model based analysis, that the system is stable with the dynamics of one state $V_{C_{o}}$ faster than the other by an order of magnitude. This observation will motivate a simple nonlinear control structure that will be explored in the sequel.

\section{A. Dynamic model analysis}

If we define:

$$
\begin{aligned}
& u_{1}=d_{1}^{2}, \\
& u_{2}=d_{2}^{2} .
\end{aligned}
$$

Then the dynamic model of the DHPS can be expressed as,

$$
\begin{aligned}
\frac{d V_{C_{1}}}{d t} & =\frac{1}{C_{1}}\left(i_{p s 1}-\frac{T\left(n V_{C_{1}}-V_{C_{o}}\right) u_{1}}{4 n L_{1}}\right), \\
\frac{d V_{C_{o}}}{d t} & =\frac{1}{C_{o}}\left(\frac{T V_{C_{1}}\left(n V_{C_{1}}-V_{C_{o}}\right) u_{1}}{4 n L_{1} V_{C_{o}}}\right. \\
& \left.+\frac{T E\left(n E-V_{C_{o}}\right) u_{2}}{2 n L_{2} V_{C_{o}}}-\frac{V_{C_{o}}}{R}\right) .
\end{aligned}
$$

Linearizing (13)-(14) them at the equilibrium point $\left(V_{C_{1}}^{*}, V_{C_{o}}^{*}, u_{1}^{*}, u_{2}^{*}\right)$ leads to:

$$
\left[\begin{array}{c}
\frac{d \tilde{V}_{C_{1}}}{d t} \\
\frac{d \tilde{V}_{C_{o}}}{d t}
\end{array}\right]=A\left[\begin{array}{c}
\tilde{V}_{C_{1}} \\
\tilde{V}_{C_{o}}
\end{array}\right]+B\left[\begin{array}{c}
\tilde{u}_{1} \\
\tilde{u}_{2}
\end{array}\right]
$$


where $\mathrm{A}$ and $\mathrm{B}$ are given as,

$$
\begin{gathered}
{\left[\begin{array}{cc}
\frac{\partial i_{p s 1}}{C_{1} \partial V_{C 1}}-\frac{T u_{1}^{*}}{4 L_{1} C_{1}} & \frac{T u_{1}^{*}}{4 n L_{1} C_{1}} \\
\frac{\left(4 n V_{C_{1}}^{*}-V_{C_{o}}^{*}\right) T u_{1}^{*}}{4 n L_{1} C_{o} V_{C_{o}}^{*}} & \frac{1}{C_{o} R}-\frac{T\left(L_{2} V_{C_{1}}^{* 2} u_{1}^{*}+L_{1} E^{2} u_{2}^{*}\right)}{4 L_{1} L_{2} C_{o}\left(V_{C_{o}}^{*}\right)^{2}}
\end{array}\right],} \\
{\left[\begin{array}{cc}
\frac{-T\left(n V_{C_{1}}^{*}-V_{C_{o}}^{*}\right)}{4 n L_{1} C_{1}} & 0 \\
\frac{T V_{C_{1}}^{*}\left(n V_{C_{1}}^{*}-V_{C_{o}}^{*}\right)}{4 n L_{1} C_{o} V_{C_{o}}^{*}} & \frac{T E\left(n E-V_{C_{o}}^{*}\right)}{4 n L_{2} C_{o} V_{C_{o}}^{*}}
\end{array}\right]}
\end{gathered}
$$

\begin{tabular}{|c|c|c|c|c|c|c|}
\hline & \multicolumn{2}{|c|}{ OP1 (150W) } & \multicolumn{2}{|c|}{ OP2 (500W) } & \multicolumn{2}{|c|}{ OP3 (850W) } \\
\hline $\mathbf{A}$ & $\begin{array}{l}-14.9 \\
111.4\end{array}$ & $\begin{array}{c}7.4 \\
-714.7\end{array}$ & $\begin{array}{l}-63.4 \\
418.6\end{array}$ & $\begin{array}{c}31.7 \\
-602.6\end{array}$ & $\begin{array}{l}-196.3 \\
1050.1\end{array}$ & $\begin{array}{c}98.2 \\
-680.8\end{array}$ \\
\hline$\lambda$ & $\begin{array}{l}-13.8 \\
-715.9\end{array}$ & & $\begin{array}{l}-39.8 \\
-626.2\end{array}$ & & $\begin{array}{c}-36.4 \\
-840.7\end{array}$ & \\
\hline
\end{tabular}

TABLE III: Linearization of the DHPS dynamic model

Table III gives the A matrix and its eigenvalues at three different operating conditions with output power of $150 \mathrm{~W}$, $500 W, 850 W$ respectively, spanning the entire range of the system. It is revealed that the dynamics of $V_{C_{o}}$ corresponding to the second eigenvalue is much faster than that of $V_{C_{1}}$. Furthermore, note from Fig.4 that $V_{C_{1}}$ equals to $V_{p s 1}$, implying that the $V_{C_{1}}$ can be governed by the power source controller. This time scale separation allows us to treat the control of the power converters as the inner loop control problem, and ignore the dynamics of $V_{C_{1}}$ which will be dealt with the outer loop control using the power source as the control actuator.

\section{B. Controller design}

Given any desired DC bus voltage $V_{\text {od }}$ and desired power command with a specified power split ratio $k$ between the two sources, the control objectives attempted in this paper is to regulate the DC bus voltage $V_{o}\left(V_{C o}\right)$ and track the power splitting command.

If we define:

$$
e=V_{o}-V_{o d}=V_{C_{o}}-V_{o d}
$$

where $u_{1}$ and $u_{2}$ are the virtual control inputs for the two DC/DC converters respectively, then, the error dynamics of the DHPS can be rewritten as:

$$
\begin{aligned}
\frac{d e}{d t} & =\frac{1}{C_{o}}\left(\frac{T V_{C_{1}}\left(n V_{C_{1}}-V_{C_{o}}\right) u_{1}}{4 n L_{1} V_{C_{o}}}\right. \\
& \left.+\frac{T E\left(n E-V_{C_{o}}\right) u_{2}}{4 n L_{2} V_{C_{o}}}-\frac{V_{C_{o}}}{R}\right) .
\end{aligned}
$$

Note that to drive the voltage regulation error to zero, it is desirable to enforce the error dynamics to have the form of:

$$
\dot{e}+\tau e=0
$$

where $\tau$ is a positive design constant. By choosing $u_{1}, u_{2}$ to satisfy:

$$
\begin{aligned}
\frac{T V_{C_{1}}\left(n V_{C_{1}}-V_{C_{o}}\right)}{4 n L_{1} V_{C_{o}}} u_{1}+ & \frac{T E\left(n E-V_{C_{o}}\right)}{4 n L_{2} V_{C_{o}}} u_{2}= \\
& \frac{V_{C_{o}}}{R}-C_{o} \tau\left(V_{C_{o}}-V_{o d}\right),
\end{aligned}
$$

we can satisfy (20) and force the voltage error to zero.

Note that:

$$
\begin{gathered}
\hat{i}_{2}=\frac{T V_{C_{1}}\left(n V_{C_{1}}-V_{C_{o}}\right)}{4 n L_{1} V_{C_{o}}} u_{1}, \\
\hat{i}_{4}=\frac{T E\left(n E-V_{C_{o}}\right)}{4 n L_{2} V_{C_{o}}} u_{2} .
\end{gathered}
$$

Since the outputs of the two DC/DC converters are connected together and the difference of the efficiency between the two DC/DC converters is negligible, the output average current ratio is equivalent to the power delivery ratio. Therefore, we define the power delivering ratio to be the ratio of the fuel cell output power over the load power:

$$
k=\frac{\hat{i}_{2}}{\hat{i}_{2}+\hat{i}_{4}} .
$$

One can then relate the power splitting ratio to the control command $u_{1}$ and $u_{2}$ as:

$$
k=\frac{V_{C_{1}}\left(n V_{C_{1}}-V_{C_{o}}\right) u_{1}}{V_{C_{1}}\left(n V_{C_{1}}-V_{C_{o}}\right) u_{1}+E\left(n E-V_{C_{o}}\right) u_{2}} .
$$

For any given power delivery ratio, we can solve (21) and (25) to derive

$$
\begin{aligned}
u_{1} & =\frac{V_{C_{o}}\left(\frac{V_{C_{o}}}{R}-C_{o} \tau\left(V_{C_{o}}-V_{o d}\right)\right)}{V_{C_{1}}\left(n V_{C_{1}}-V_{C_{o}}\right)} \\
& \times \frac{4 n L_{1} L_{2} k}{k T L_{2}+(1-k) T L_{1}} \\
u_{2} & =\frac{V_{C_{o}}\left(\frac{V_{C_{o}}}{R}-C_{o} \tau\left(V_{C_{o}}-V_{o d}\right)\right)}{E\left(n E-V_{C_{o}}\right)} \\
& \times \frac{4 n L_{1} L_{2}(1-k)}{k T L_{2}+(1-k) T L_{1}}
\end{aligned}
$$

This controller can achieve: (1) voltage regulation which is guaranteed by (20); (2) power tracking control which is benefited from (25). Moreover, no current sensor is needed for the power tracking control. This current sensorless feature can reduce both size and cost of the system and will potentially benefit practical applications. This controller is verified with simulations and experiments, and the results are shown at the next subsection.

\section{System performance verification}

The nonlinear controller is evaluated using the real hardware testbed, and the results for $R=6.4$ and $\tau=2000$ are shown in Fig.6a and Fig.6b for the step change power command and truncated $10 \mathrm{~Hz}$ sinusoidal command. Both the simulation and the experiments results confirmed that the desired power ratio trajectory is tracked very well without 

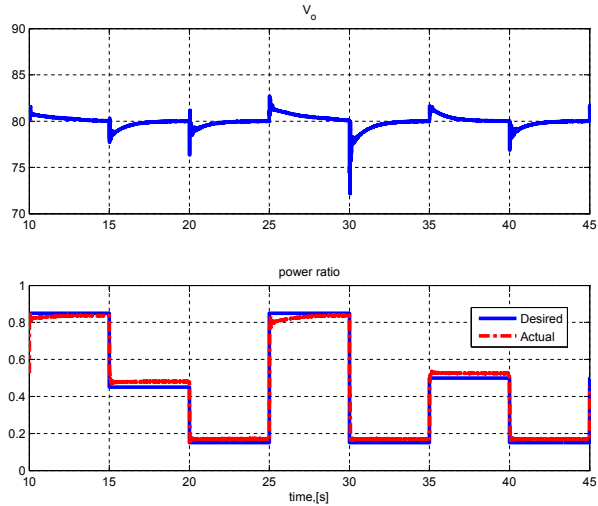

(a)
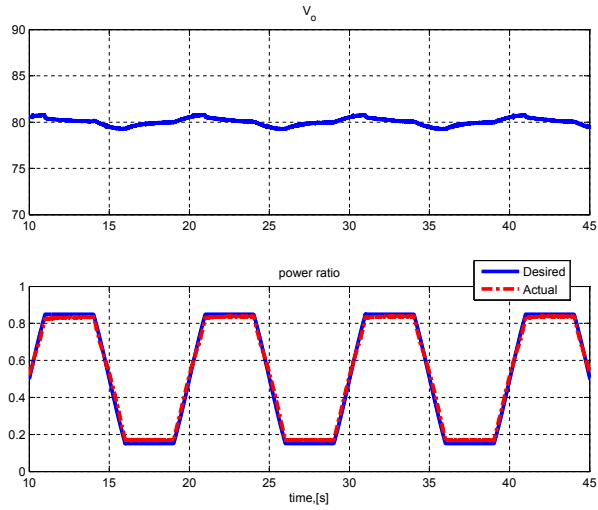

(b)
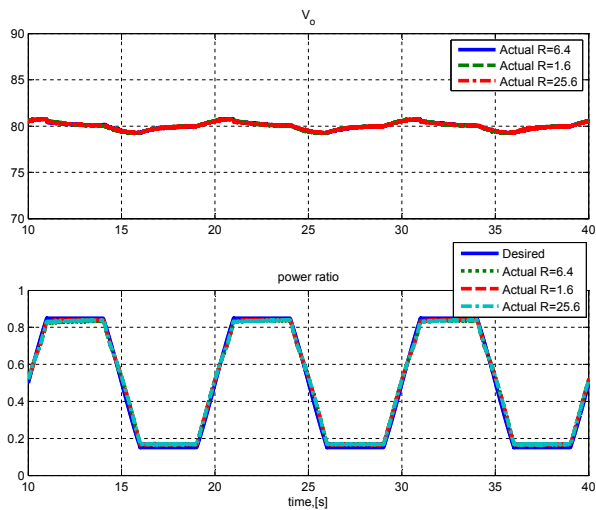

(c)

Fig. 6: Evaluation of nonlinear controller with experiment.

using a current sensor, and the output voltage $V_{o}\left(V_{C o}\right)$ is regulated to $V_{o d}$. The transient performance of the voltage regulation, however, is still an issue, especially for step input as shown in Fig.6a. This will be addressed in our future work.

Finally, by introducing an additive perturbation to the controller's parameters, namely $R$, the robustness of the controller is evaluated. Fig.6c verified the performance of the system by comparing the responses for the perturbed controller ( $R=1.6$ and $R=25.6$ ) to the original one $(R=6.4)$. Note that for the values of $R$ ranges from $1.6 \Omega$ to $25.6 \Omega$, the response is essentially unchanged.

\section{CONCLUSION}

In this paper, we investigated a DC hybrid power system that involves multiple sources and full bridge DC/DC converters. Two models are developed to serve two different purposes: the physical model that is used as the virtual hardware for control performance evaluation, and the low order large signal dynamic model that facilitates the control design. Both models have been validated with experimental results. Based on the low order dynamic model, a nonlinear controller is developed and verified with simulations and experiments. Voltage regulation is achieved while the power tracking is guaranteed. Moreover, no current sensor is needed for implementing the power tracking control. Several issues have been identified in the control design process that warrant future research. For example, current DHPS configuration only can deal with passive resistant load. Bidirectional DC/DC converter and energy storage bank should be added to support active loads; the control law is derived based on the fact that $V_{C_{1}}$ equals output voltage of power source and the assumption that output voltage of power source is regulated by a outer loop controller, the coupling effect between the inner loop controller and the outer loop controller can be analyzed in the future.

\section{REFERENCES}

[1] T. Senjyu, T. Nakaji, K. Uezato, and T. Funabashi,“ A hybrid power system using alternative energy facilities in isolated island," IEEE Transaction on Energy Conversion pp.406-414 JUN 2005

[2] M.B. Burnett, and L.J. Borle, "A power system combining batteries and supercapacitors in a solar/hydrogen hybrid electric vehicle," IEEE Conference Vehicle Power and Propulsion, 7-9 Sept. 2005

[3] W.Z. Gao,"Performance comparison of a fuel cell-battery hybrid powertrain and a fuel cell-ultracapacitor hybrid powertrain," IEEE Transactions on Vehicular Technology, May 2005

[4] Y.H. Xie, G. Seenumani, J. Sun, Y.F. Liu, and Z. Li, "A PC-Cluster Based Real-Time Simulator for All-Electric Ship Integrated Power Systems Analysis and Optimization," IEEE Electric Ship Technology Symposium (ESTS2007), May 21-23, 2007

[5] C.W. Deisch,"Simple switching control method changes power converter into a current source," PESC '78; Power Electronics Specialists Conference, Syracuse, N.Y., June 13-15, 1978

[6] S. Abe, and T. Ninomiya, "Effect of Peak Current Mode Control on Transient Response for VRM Application," CES/IEEE 5th International Power Electronics and Motion Control Conference, 2006. IPEMC '06, Vol. 3, 14-16 Aug., 2006.

[7] W. Tang, F.C. Lee, and R.B. Ridley, "Small-signal modeling of average current-mode control," IEEE Transaction on Power Electronics, vol. 8, Mar. 1993.

[8] P. Midya, P.T. Krein, and M.F. Greuel, "Sensorless current mode control-an observer-based technique for DC-DC converters," IEEE Transactions on Power Electronics, Vol. 16, July 2001.

[9] S.G. Luo, Z.H. Ye, R.L. Lin, and F.C. Lee, "A classification and evaluation of paralleling methods for power supply modules," 30th Annual IEEE Power Electronics Specialists Conference, PESC 99, 27 June-1 July 1999

[10] D.J. Perreault, R.L. Selders, Jr., and J.G. Kassakian, "Frequencybased current-sharing techniques for paralleled power converters," IEEE Transactions on Power Electronics, July, 1998.

[11] V.J. Thottuvelil, and G.C. Verghese, "Analysis and control design of paralleled DC/DC converters with current sharing," Twelfth Annual Applied Power Electronics Conference and Exposition, 1997. APEC'97, Vol. 2, 23-27 Feb., 1997. 